\title{
Savoirs du Nord
}

\section{Christophe Didier}

\section{(2) OpenEdition}

Journals

Édition électronique

URL : https://journals.openedition.org/rbnu/1947

DOI : 10.4000/rbnu.1947

ISSN : 2679-6104

\section{Éditeur}

Bibliothèque nationale et universitaire de Strasbourg

\section{Édition imprimée}

Date de publication : 1 novembre 2013

Pagination : 7

ISBN : 9782859230517

ISSN : 2109-2761

\section{Référence électronique}

Christophe Didier, «Savoirs du Nord », La Revue de la BNU [En ligne], 8 | 2013, mis en ligne le 01 novembre 2013, consulté le 24 mai 2021. URL : http://journals.openedition.org/rbnu/1947 ; DOI : https://doi.org/10.4000/rbnu. 1947

\section{(C) $10(0$}

La Revue de la BNU est mise à disposition selon les termes de la Licence Creative Commons Attribution - Pas d'Utilisation Commerciale - Partage dans les Mêmes Conditions 4.0 International. 


\section{LE DOSSIER}

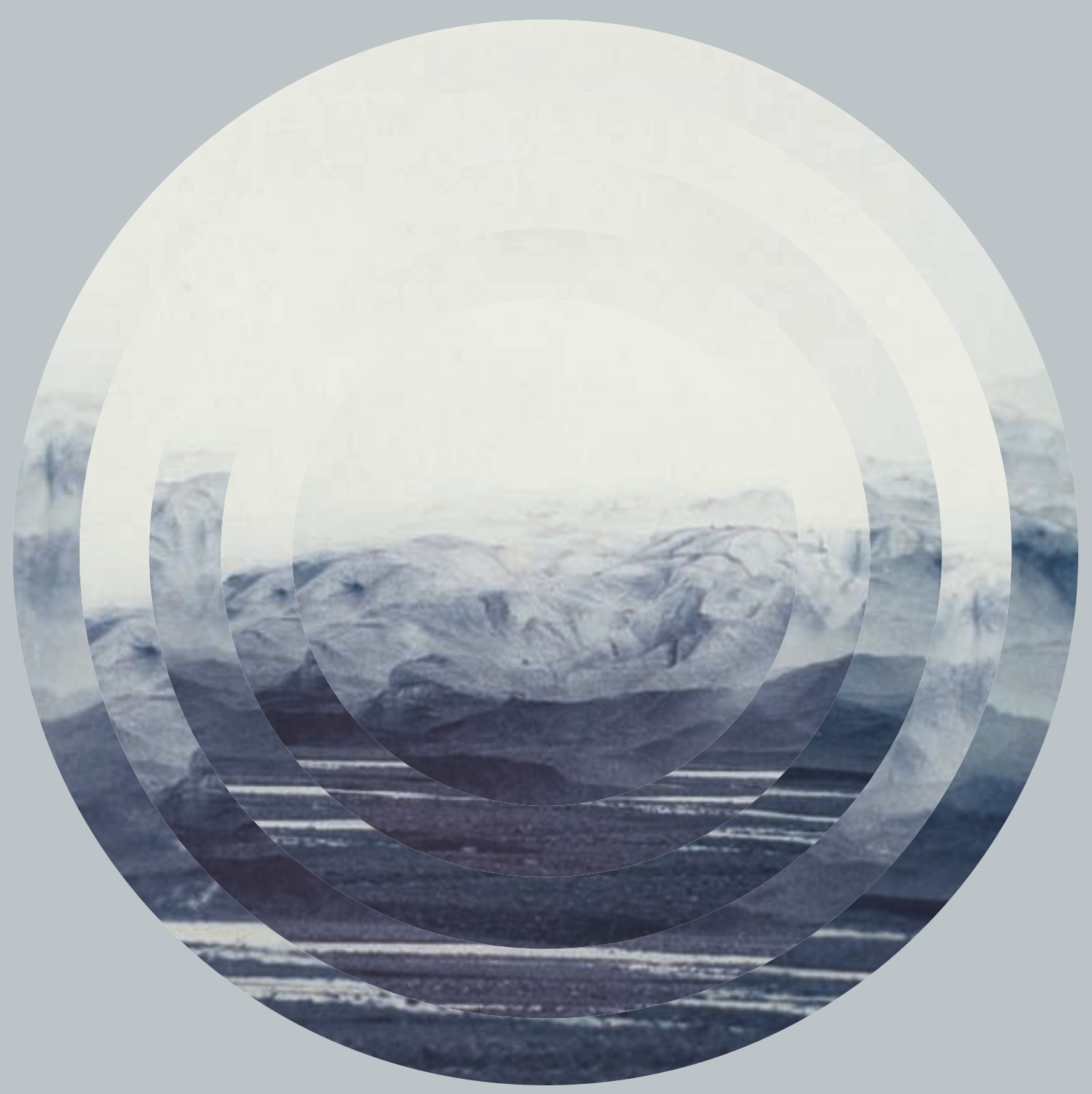




\section{Savoirs du Nord}

Le Nord, lointain et proche à la fois... Connu pour ses architectures contemporaines, ses designers de renom contribuant à diffuser avec succès l'image d'un certain " nordic way of life "; reconnu pour son cinéma, familier et déroutant à la fois, de Bergman à Kaurismäki, et tout récemment médiatisé par l'audience de la série télévisée Borgen... sans parler des succès populaires de ses romans policiers ou de l'œuvre de Paasilinna. Le Nord qui reste cependant lointain et en définitive peu visité par le reste de l'Europe, qui n'en maîtrise pas les langues et redoute son climat. Le Nord, malgré tout puissamment ancré dans l’imaginaire collectif, des Vikings aux touristes suédoises...

C'est de cette Scandinavie, vue au prisme de ce qu'en révèlent les fonds d'une bibliothèque, qu'il est question dans ce numéro. Une partie de l'Europe en quête de reconnaissance par ses voisins du sud, et que l'on voit pour ce faire se donner les moyens, intellectuels et culturels, de se construire une identité. Loin des clichés sur les étendues figées du Grand Nord, les articles de ce numéro font revivre des échanges intellectuels, des découvertes et influences réciproques qui ont relié, dès le moyen-âge mais plus encore à partir du $18^{\mathrm{e}}$ siècle, l'Europe latine et le monde germanique " continental » à la Scandinavie prenant place, petit à petit, dans le concert européen des nations.

Les ouvrages scandinaves anciens que la Bibliothèque nationale et universitaire de Strasbourg conserve dans ses fonds sont plus remarquables par leur qualité que par leur nombre; certains sont rares en Scandinavie même et méritent d'autant plus d'être mis en valeur. C'est l'entreprise que s'est fixée la bibliothèque, en collaboration avec le Département d'études scandinaves de l'Université de Strasbourg et son directeur, Thomas Mohnike, tout d'abord par la numérisation de la partie la plus remarquable de ce fonds, désormais disponible pour la recherche. On trouvera dans ce numéro quelques exemples d'ouvrages ainsi remis en lumière.
Les réseaux patiemment tissés et établis depuis des siècles sont aussi ceux de la recherche actuelle qui trouve dans ce numéro sa parfaite illustration : produit d'un projet de chercheurs de Strasbourg, Bâle et Fribourg-en-Brisgau dans le cadre du réseau EUCOR en études scandinaves, il leur associe quelques hauts lieux de la recherche française sur ces pays, Bibliothèque nationale de France et plus encore, Bibliothèque Sainte-Geneviève et son fameux " fonds nordique ". Le poète Jesper Svenbro, membre de l'Académie suédoise, dont nous avons le plaisir de publier deux inédits, nous rappelle indirectement que c'est aussi du Nord que nous vient, chaque année, une des récompenses les plus médiatiques avec la remise des prix Nobel. D'une identité qui se cherche, se construit et tente de s'imposer, à une institution donnant le ton à la planète, dans les domaines de compétence qu'elle s'est attribués : c'est un pan de l'histoire culturelle du Nord, lointain et proche à la fois, que ce numéro de La Revue nous invite à redécouvrir.

\section{Christophe Didier}

